\title{
Psychological Argumentation in Confucian Ethics as a Methodological Issue in Cross-Cultural Philosophy
}

\author{
Rafal Banka ${ }^{1}$
}

Published online: 3 October 2016

C) The Author(s) 2016. This article is published with open access at Springerlink.com

\begin{abstract}
Graham Priest claims that Asian philosophy is going to constitute one of the most important aspects in 21st-century philosophical research (Priest 2003). Assuming that this statement is true, it leads to a methodological question whether the dominant comparative and contrastive approaches will be supplanted by a more unifying methodology that works across different philosophical traditions. In this article, I concentrate on the use of empirical evidence from nonphilosophical disciplines, which enjoys popularity among many Western philosophers, and examine the application of this approach to early Chinese philosophy. I specifically focus on Confucian ethics and the study of altruism in experimental psychology.
\end{abstract}

Keywords Comparative philosophy · Confucian ethics · Philosophical methodology · Experimental evidence

\section{Introduction}

In his paper "Where is Philosophy at the Start of the Twenty-first Century?", Graham Priest formulates a prediction concerning the expected scope of future philosophical research. He reconstructs the developmental trajectory of philosophy from the turn of the 19th and 20th centuries, which begins with the domination of German Idealism, accompanied by the three minor "-isms": empiricism, existentialism, and Marxism (Priest 2003: 90). Subsequently, this is successfully surpassed by "new logic" and phenomenology, which leads to the development of analytic and continental traditions

Rafal Banka

rafal.banka@uj.edu.pl

1 Centre for Comparative Studies of Civilisations, Faculty of Philosophy, Jagiellonian University, ul.Grodzka 52, II p., pok. 120, 31-044 Krakow, Poland 
in philosophy respectively. This stage, referred to by Priest as the "optimistic phase," is followed by the "pessimistic phase" that dismantles its predecessor. ${ }^{1}$ The current condition is characterized by fragmentation, consisting in a diversity of views presented by the philosophical milieu (Priest 2003: 91-93, 94).

Priest proposes three main strands, which in his opinion will define the philosophical trajectory in the 21st century: feminism, cognitive science, and Asian philosophy (Priest 2003: 95). Two observations can be made regarding the latter two. First, despite cognitive science being interdisciplinary, Priest discusses it in the context of philosophical research. Admittedly, this does not suggest that cognitive science can become a philosophical subdiscipline similar to metaphysics or epistemology. Priest seems to be more inclined to the view that recently philosophy has manifested a growing tendency to incorporate scientific research, by which it becomes naturalized in terms of methodology. In reality, this state of affairs is not so completely new, as Western philosophical theories quite often resort to their contemporary status of science to argue for their premises. For instance, in contemporary metaphysics, Ned Markosian's variant of creating mereological objects defined by spatial contact is disproven by referring to the structure of an atom where there is a considerable distance between the particles constituting it (Markosian 2008: 348-349). Other philosophers also include Descartes, who in Passions of the Soul viewed animals in mechanical terms; and Julien Offray de La Mettrie, who in his L'Homme Machine (Human Mechanism) shared a similar idea with regard to humans. Furthermore, many issues originally investigated by philosophers find their resolution in science ${ }^{2}$ - or even give rise to new scientific disciplines. The latter can be exemplified by psychology, initially a philosophical enquiry into the nature of the human mind, which can be traced back to Plato's philosophy. With increasing intensity of research, it would finally evolve into an independent empirical science by the end of the 19 th century. ${ }^{3}$ These features indicate an important methodological aspect of Western philosophy, namely that it has always been in considerable and necessary proximity to science, or sometimes even in continuity with it.

Second, Priest's inclusion of Asian philosophy among the most promising trends in contemporary philosophy broadens the horizon of research from the thus far localWestern out toward global or at least transcultural philosophy. Priest even concludes that the philosophical center will be shifted to India and China, thereby approaching "the true globalization of philosophy" (Priest 2003: 99). This relocation, not only in terms of geography but also object of research, introduces a noteworthy qualitative difference from the existing comparative liaisons between Asian and Western philosophical traditions. Instead of pursuing the discussion of (in)commensurability between the two traditions, the global approach can give rise to a new methodology, aiming at encapsulating them. This subsequently could allow the focus to shift toward philosophical problems discussed from an integrated transcultural, or even more preferably, pancultural standpoint.

\footnotetext{
${ }^{1}$ The analytic and continental traditions are disassembled by W. V. O. Quine and Jacques Derrida respectively (Priest 2003: 93).

${ }^{2}$ The most famous example would probably be Descartes's view concerning the pineal gland as a psychophysical transmitter. It was later discovered that it produces melatonin (Lokhorst 2016).

${ }^{3}$ Usually the origin of psychology as a separate discipline is associated with the establishment of the first psychological lab by Wilhelm Wundt in 1879 .
} 
It is legitimate to suppose that Priest's subdivision into the three trends allows their natural integration with one another, thanks to which an amalgamation of cognitive science and Asian philosophy can be achieved. Thus, from a heuristic perspective, the issue of naturalized philosophy can also reach the Asian tradition, or at least such a plausibility should be given a preliminary consideration. Whereas the methodological linkage with science constitutes an important feature of Western philosophy, this cannot be said of the Chinese philosophical tradition. The production of philosophical knowledge in both contexts took place in significantly different and multifaceted circumstances that, according to Richard Nisbett, even include environmental conditioning. ${ }^{4}$ Therefore, some deep differences on philosophical and metaphilosophical levels may constitute an obstacle to the plausibility of successful collaboration between Chinese thought and scientifically-oriented approaches.

The above concern should not be taken too far, however. Confucian ethics constitutes a most representative argument for it. One of the earliest examples is Francisco J. Varela's discussion on the cognition-consciousness relation with references to Mencius (Mengzi 孟子), Laozi 老子, as well as vajrayāna Buddhism (Varela 1999: 26-32). Varela smoothly moves across different philosophical traditions and refers them to scientific data, successfully dismissing the incompatibility threat for the benefit of his research objectives.

More importantly, referring to scientific evidence can also be found in recent publications by scholars specializing in Chinese philosophy. This can be exemplified by The Philosophical Challenge from China, a book devoted to new approaches in Chinese philosophy, edited by Brian Bruya, a philosopher working in both Chinese philosophy and cognitive science. Among contributors to the book, one can find David Wong, SEOK Bongrae, and Hagop Sarkissian, whose research combines Confucian ethics with cognitive science, neuroscience, or experimental psychology (Bruya 2015). Edward Slingerland deserves to be mentioned as a scholar who not only applies scientific methodology to Chinese philosophy but is an advocate for combining humanities and science on a larger scale. ${ }^{5}$ Despite not belonging to mainstream Chinese philosophical research, this new trend shows that at least some issues in Chinese thought can be investigated with the aid of science.

In this article, I would like to discuss the question of how referring to the results of empirical sciences influences philosophical methodology. This question will be addressed on a specific level. I shall examine Confucian-Mencian ethics in terms of altruistic motivation by supporting it with experimental psychology argumentation, as conducted and presented by C. Daniel Batson (Batson 1991).

\section{Confucian Ethics: Departing from Behavior}

Before I proceed to discuss the issue of altruism in the Mencius, it is necessary to highlight some features of Confucian ethics that justify its compatibility with experimental psychology argumentation.

\footnotetext{
${ }^{4}$ Richard Nisbett traces the differences between Western and Chinese civilizations, including philosophy, even to natural environment factors, economy, folk mentality, and so on (Nisbett 2003: 1-49).

${ }^{5}$ Slingerland and Collard 2012, and Slingerland 2008 are thorough presentations of this idea.
} 
From a typological perspective, Confucian ethics classified as virtue ethics reveals the potential for discussion from a psychological angle. Rosalind Hursthouse provides a description of virtue ethics, which in contrast with deontology and consequentialism is mostly concerned with "the virtues or moral character" (Hursthouse 2013). Therefore, it is primarily oriented at developing one's character traits, which are regarded as a generic feature of a moral person or an evaluating measure in this respect.

Confucian moral philosophy identifies the moral character with ren 仁. The term has many translations due to its broad semantic field supervening on different contexts. ${ }^{6}$ Among others, it can be perceived as a special form of sensitivity, tantamount to being good. More properly, ren should be conceived of as "one's being ren," which corresponds to one's actual manifestation of sensitivity rather than its encapsulation within some ethical concept. Another semantic layer of ren is understood as humanity. ${ }^{7}$ In this sense, one's ren is tantamount to one's advancement in becoming a human being.

Ren as a psychological trait is necessarily forged through human practice, on multiple levels of social interaction, stretching from family to state. It is realized by means of rituals/propriety ( $l i$ 禮), which prescribe a specific behavioral repertoire for a given individual, depending on her specific place in the network of social relations. Concurrently, ren emerges in practice and as practice, instead of being represented or applied. In this way, practice constitutes the self-cultivation of an individual's ren as long as the proper form of behavior is abided by. As can be seen, ren does not constitute a psychological faculty that is independent from human practice but emerges in enactment. In other words, the moral agent's character traits extend the subject beyond the mind into action.

Ren as the objective in Confucian moral projects is also understood in relation to wisdom. Therefore, an exemplary person (junzi 君子) or a sage (sheng 聖) who is advanced in her ren-cultivation concurrently treads the path of cognition. The fact that achieving the moral ideal of becoming ren is identified with the pursuit of wisdom shows that Confucianism is concerned with practical knowledge. This can be testified to by, for example, Analects (Lunyu 論語) 1.7, where proper practice as knowledge is valued even higher than the intellectual advancement of a person (see Waley 1997: 2). Another example can be taken from the famous Mencius 2A6. One of the Confucian virtues constituting good nature-knowledge ( $z h i$ 智) - is conspicuously viewed in terms of practical knowledge. Contrary to a rationalistic approach to morality, here ethical wisdom consists in the practical discrimination between right and wrong-shifei 是非 (Mencius 2A6). This also confirms the fact that in early Confucianism, knowledge is enactive-emergent rather than attainable in a purely speculative character.

The identity of the moral and epistemic order as well as the enacted character of ren is an important feature of Confucian ethical discourse. Since practice consists in

\footnotetext{
${ }^{6}$ D. C. Lau and James Legge in their translations of the Mencius, for instance, translate ren as "benevolence" (Lau 1984; Legge 1985). Translations of the Analects by Arthur Waley and Edward Slingerland use "goodness" (see Van Norden 2008: 202). As regards Bryan W. Van Norden's translation of the Mencius, he uses "benevolence" but in the appended glossary he makes a remark that ren in 7B16 has a wider meaning, with a shade of "humaneness" (Van Norden 2008: 202). A completely different understanding is proposed by Roger T. Ames and Henry Rosemont in their translation of the Analects. In the Introduction, they propose the following translations of ren: "authoritative conduct," "to act authoritatively," "authoritative person," and compare them to other existing renderings of ren into English (Ames and Rosemont 1998: 48-51).

${ }^{7}$ It is also suggested by the popular interpretation of the character ren 仁 as the compound of ren 人 and er 二.
} 
moulding the human mind, both in a moral and cognitive respect, Confucian ethics discourse allows one's character traits to be described based on behavior. This can be illustrated by Analects 1.11, where Confucius provides evidence for stating one's filial piety-xiao 孝: "If for the whole three years of mourning he manages to carry on the household exactly as in his father's day, then he is a good son indeed" (see Waley 1997: 6-7). The judgment concerning one's virtue is based on whether a son's behavior accords with a form of conduct appropriate to the situation of mourning. A more direct reference to the behavior-personality trait is made in Analects 12.1: "He who can himself submit to ritual is good" (see Waley 1997: 144-145). Here the passing moral evaluation is also based on the underpinning enactment and assumed entraining by $l i$.

The above assumption pervades the narration of both the Analects and the Mencius, where the people under discussion are presented in terms of, for instance, obeying the rules of how to properly perform ceremonies instead of concentrating on their "internal psychological faculties." This approach confirms the Confucian notion of the individual, who is primarily constituted of the moral roles appropriate to her position within a social network of relations with others. One can state that this conception is a reversal of Sartre's existence preceding essence (Sartre 2007: 20), for which relations are secondary. Confucians treat essences as primary. Therefore, it is quite understandable that Confucian discourse not only focuses on behavior but also endows it with the considerable potential of revealing character traits.

Concurrently, it has to be emphasized that the interpretation of Confucians as behavioristic reductionists entertaining the idea that the moral project culminates only in developing certain patterns of behavior has to be excluded. In Analects 3.3, Confucius asks rhetorically: "A man who is not Good, what can he have to do with ritual?" (see Waley 1997: 24-25). This presupposes that proper behavior is by necessity coupled with adequate moral qualities which affectively engage the agent, and that indifferent performance is insufficient for moral qualification. Thus, Confucianism does not assume a model in which a moral agent fulfills herself in merely internalizing proper forms of social interaction. Behavior is crucial in constituting the emotional dimension of ren.

The above discourse feature allows a sound premise to emerge that Confucian ethics can be viewed from the perspective of experimental psychology. Despite being an empirical science, psychology overlaps considerably with Confucianism in terms of methodology; they both consider human reactions and interactions in specific situations as indicatory of, inter alia, personality traits. Therefore, experiment results can be integrated as argumentation into Confucian moral philosophy.

\section{The Altruism Issue: The Case of Mencius $2 \mathrm{A6}$}

In my discussion, I assume Batson's definition of altruism as "a motivational state with the ultimate goal of increasing another's welfare" (Batson 1991: 6). The differentiating feature is ascribed to what motivation lay behind an action. In order to be labelled altruistic, another's benefit must be the ultimate, as opposed to instrumental, goal.

In my presentation of altruism in Confucian ethics, I refer to Mencius 2A6, which appears to be most appropriate for the discussion for several reasons. First, it departs from the conception of the four sprouts (siduan 四端), which is an explanation of good 
human nature, as postulated by Confucian-Mencian ethics. Second, it thoroughly presents a situation which evidently argues for an altruistic approach in terms of the agent's motivation. Finally, Mencius shows and enumerates the possible alternative motivations that are rejected in favour of the altruistic one.

The situation described by Mencius serves as an explanation of his claim that all people possess a sense of compassion (buren ren zhi xin 不忍人之心; Mencius 2A6). In this way, he somewhat presets the interpretation, even considering the fact that competing options are mentioned. Mencius says that if the moral agent suddenly ( $\mathrm{h} h \mathrm{~h}$ 乍) notices a child who is about to fall into the well, she would be "moved to compassion" (D. C. Lau's translation of ceyin 惻隱; see Lau 1984). The fact that the affective state emerges naturally is presupposed and accentuated by the reaction being sudden. Mencius attributes this to good human nature and eliminates other explanations by saying that the agent is not motivated by:

(a) "get[ting] in the good graces' of the child's parents,"

(b) "win[ning] the praise of his fellow villagers or friends,"

(c) "dislik[ing] the cry of the child." (Mencius 2A6; see Lau 1984: 82)

These possible alternative motivations seem to be excluded on the grounds of being impossible in comparison with the "evident" altruistic motivation manifested by compassion. The firm foundation for Mencius' altruistic claim is provided by referring to the innate four sprouts (siduan), whose practical development guarantees being good. Compassion here fulfills an important role since it is the sprout of ren (ceyin zhi xin, ren zhi duan ye 惻隱之心, 仁之端也; Mencius 2A6). The affective foundation of ren seems to sufficiently confirm Mencius in the evident altruistic motivation of the agent.

However convincing the example and explanation may seem, the interpretation varies among philosophers. Bernard Mandeville (1670-1733), for instance, describes a very similar situation but represents a completely different standpoint than Mencius, namely that human actions are always motivated by self-interest. He provides a situational example intertwined with ethical evaluation to illustrate apparent altruist actions, and views it in terms of agent's motivation:

There is no Merit in saving an innocent Babe ready to drop into the Fire: The Action is neither good [n] or bad, and what Benefit soever the infant received, we only obliged our selves; for to have seen it fall, and not strove to hinder it, would have caused a Pain, which self-preservation compell'd us to prevent. (Mandeville 2010: 82-83)

The juxtaposition of Mandeville's and Mencius' completely different intuitions concerning human nature, apart from showcasing the commonplace coexistence of incongruent philosophical conceptions, also indicates an important methodological issue. In constructing their argumentation, philosophers often refer to everyday experience. In the case of ethical issues, the material most often consists of human behavior, which is subjected to interpretation that supports a philosophical statement. The material is oftentimes collected, selected, and interpreted in an unsystematic way, which casts doubt on its contribution to a strong argument. 
Using material from experience can be conducted in a more systematic way, which ensures higher accuracy manifested by a more comprehensive and thorough processing of the raw data. A contemporary epistemologist, for instance, is more likely to examine perception by referring to physiology rather than her personal experience. In the same way, ethical statements can gain more validity when the interpreted data come from systematically conducted experiments that follow standards connected with, for example, bias elimination, impairment caused by external factors or interference with a different aspect of the study. For this particular reason, resorting to experimental psychology as a systematic empirical study of human behavior allows an examination of to what extent Mencius' altruism conception is sound, as well as whether debunking the competing egoistic motivations finds any experimental confirmation.

\section{Mencius 2 A6 Arguments For and Against Altruism versus Experiments}

The linkage between experiments discussed below and Mencius' conception of altruism is established on account of the fact that both Mencian compassion and Batson's empathy, being the same or a very similar emotion, underpin altruistic motivation. Concurrently, it has to be mentioned that the discussed fragment from the Mencius uses the vocabulary item ceyin 惻隱, which is in semantic proximity to compassion and sympathy. Batson's empathy, despite being semantically discrete, can be viewed in terms of compassion. In order to support the adequacy of referring Batson's empathy to Mencian compassion, I refer briefly to a thorough analysis of compassion and empathy in Stephen Darwall's "Empathy, Sympathy, Care” (Darwall 1998).

Darwall, among others, focuses on Mencian ceyin and empathy from the experiments that I discuss below. He understands D. C. Lau's translation of "compassion" 8 from Mencius 2A6 as "sympathetic concern or sympathy." It "responds to some threat or obstacle to an individual's good or well-being," has "that individual himself as object," and "involves concern for him, and thus for his well-being, for his sake." It is thus specified concern that allows Darwall to draw the distinction between sympathy and empathy. He generally understands empathy as primarily consisting in feeling what one imagines the individual taken as an object of one's own empathy feels (Darwall 1998: 261). It does not have to include concern for another's well-being, which is an indispensable composite of sympathy.

Darwall further distinguishes between projective and proto-sympathetic empathy. The former consists in projecting into another's perspective. As regards the latter, it enriches the projective empathy perspective with concurrent focus on another and her feelings (which she may not necessarily be conscious of) (Darwall 1998: 270-271). What should be noticed is that proto-sympathetic empathy shares with sympathy the concern for another's well-being. This fact is important in light of another remark of Darwall that proto-sympathetic empathy is close to Batson's motivating empathy. Although Batson uses the word "empathy," he describes motivation as being oriented toward increasing the well-being of another (Darwall 1998: 273). Thus, we can assume that the subjects in the experiments are motivated by either sympathy or at least protosympathetic empathy. Darwall himself remarks that Batson actually manipulates by

\footnotetext{
${ }^{8}$ Darwall does not refer to the original Chinese text.
} 
means of the two forms of empathy and there is a "psychological connection between empathy and sympathy" that prompts sympathy-led motivation (Darwall 1998: 273). Accordingly, the experiments can be regarded as ones that test the relation between sympathetic concern and altruism. This creates a reference point between Batson's empathy and Mencian ceyin.

In my discussion of argumentation in 2A6, I assume that the situation presumes the action/motivation to help the child. I propose a clarification of Mencius' argument for altruistic motivation in the following way:

The motivation for helping the child has the child's need as the ultimate end. It is guaranteed by compassion, the basis of ren (Mencius 2A6). The agent's action of helping would not be ren if it were self-interested.

As regards other possible motivations rejected by Mencius, they can be described in the following way:

(1) "Get[ting] in the good graces of the child's parents" (Mencius 2A6; see Lau 1984: 82). The motivation for helping the child is social reward, which is represented here by getting in the parents' good graces. Mencius claims that egoistic motivation cannot underlie the described feeling.

(2) "Win[ning] the praise of his fellow villagers or friends" (Mencius 2A6; see Lau 1984: 82). The moral agent is mostly concerned with satisfaction "caused" by positive appraisal in terms of socially established morality, and rescuing the child is a means to an end. As in (1), Mencius claims the feeling does not result from such egoistic motivation.

(3) "Dislik[ing] the cry of the child" (Mencius 2A6; see Lau 1984: 82). The motivation for helping is to put an end to the child's crying, which the agent experiences as repugnant. The ultimate aim is alleviating one's own discomfort, and as in (2), benefitting the child is instrumental. Similarly to (1) and (2), Mencius excludes this egoistic motivation.

I will analyze the negative cases (1)-(3) with reference to relevant experiments. Since the experiments I refer to compare selected egoistic and altruistic motivations, the hypothesis propounded by Mencius is discussed throughout the two cases. Before I proceed to the experiments, for the sake of clarity I shall briefly outline the general idea of Batson's experimental study and the way in which it verifies his empathy altruism hypothesis.

Batson's study consists in proving his "empathy-altruism" (EA) hypothesis, according to which empathy evokes altruistic motivation to reduce the other's need (Batson 1991: 90). As can be seen, the hypothesis is conceived in terms of motivation. This is also the case in the three competing egoistic hypotheses discussed below.

Batson refers to experiments which show evidence that subjects in a state of empathy are more likely to help others in need (e.g., Coke et al. 1978; Dovidio, Allen, and Schroeder 1990; see Batson 1991: 95). Following this, Batson claims that in a state of high empathy, the motivation is exclusively altruistic (Batson 1991: 97). The aim of his study is to prove the altruistic basis of the motivation as opposed to the 
egoistic motivation. ${ }^{9}$ Batson claims that in experiments comparing the EA hypothesis with one of the competing egoistic hypotheses, the two different motivations would produce two different arrays of responses to the same staged situation. Thanks to this, the helping rate for each motivation can be measured and compared. The comparison result shows which of the tested hypotheses is more probable. Apart from the last one, all experiments involve the manipulation of the situation parameters that are expected to influence the helping rate. Empathy manipulation examines the relation between the magnitude of empathy and the helping rate. Apart from manipulating the empathy, depending on the particular egoistic motivation being tested against the EA hypothesis, the manipulation of a specific parameter is introduced. The parameters for the three egoistic hypotheses discussed in this article are: escape ease, negative social evaluation potential, and feedback availability. Manipulating these conditions in staged situations is designed to show how behavior patterns with or deviates from the tested hypotheses, in high as well as low empathy condition.

I begin my analysis with the third motivation, according to which the agent feels uncomfortable and in order to eliminate the source of this state instrumentally helps the child, whereas the ultimate end is the elimination of the unpleasant stimulus. The hypothesis based on this type of motivation is referred to by Batson as the "aversivearousal reduction" (AAR) hypothesis. Accordingly, "becoming empathically aroused by witnessing someone in need is aversive and evokes motivation to reduce this aversive arousal" (Batson 1991: 109). One can interpret Mencius' dismissing this motivation in the way that empathy can only co-occur with altruistic motivation and there cannot be any correlation between aversion and empathy.

In his discussion of AAR, Batson mostly concentrates on experiments concerning the empathy-affective arousal connection. His two experiments that I will discuss here test the helping rate in both low and high empathy states. In order to differentiate between the AAR egoistic motivation and the EA hypotheses, escape ease manipulation is introduced. Batson regards this factor as an adequate way of testing the two hypotheses in parallel on the grounds that by choosing escape one might reach the egoistic goal (reducing one's arousal) while concurrently not removing the stimulus (another's suffering), that is, not reaching the altruistic goal (Batson 1991: 110). The AAR-EA hypotheses contrastive predictions concerning the helping rate are as follows:

AAR hypothesis:

Easy escape and low empathy: low helping rate.

Easy escape and high empathy: low helping rate.

Difficult escape and low empathy: high helping rate.

Difficult escape and high empathy: high/very high helping rate. (Batson 1991: 111)

\section{EA hypothesis:}

Easy escape and low empathy: low helping rate.

Easy escape and high empathy: high helping rate.

Difficult escape and low empathy: high helping rate.

Difficult escape and high empathy: high helping rate. (Batson 1991: 111)

\footnotetext{
${ }^{9}$ It should be remarked that Batson's experimental study on altruism is not unanimously recognized. His response to critics is included in Batson 2011.
} 
The clash occurs in the high empathy condition with the easy escape. Egoistic persons, in order to terminate their aversion, are likely to resort to escape, whereas altruisticallymotivated ones should remain insensitive to this factor. Faced with a difficult escape, the high help rate should be similar for AAR and EA as egoistically-motivated persons incline toward the high-cost termination of their aversion by helping the person in need (Batson 1991: 110-111).

The first experiment is named "A Shocking Situation: Observing Elaine Perform under Aversive Condition," and was conducted by Batson et al. in 1981. The participants of the experiment are female undergraduates observing Elaine (confederate) undergoing ten unpleasant electric shocks, which were supposed to evoke their aversion (Batson 1991: 113). In order to manipulate the ease of escape, the participants were informed that if after two shocks they did not help Elaine, they would not observe the remaining eight of the ten shocks (easy escape condition) or they would have to see all of them (difficult escape condition). As regards empathy manipulation, the participants were presented a 14-value questionnaire allegedly filled out by Elaine. To elicit a state of high empathy, Elaine's values and interests were very similar to those of the particular participant, whereas they were extremely dissimilar when a low empathy state was elicited (Batson 1991: 115).

The result of the experiment was as follows:

Easy escape and low empathy: 0.18

Easy escape and high empathy: 0.91

Difficult escape and low empathy: 0.64

Difficult escape and high empathy: 0.82. (Batson 1991: 116)

The data were interpreted that easy escape did not affect the helping rate in the high empathy condition, which disconfirms the AAR and confirms the EA hypothesis. However, in the low empathy condition, the impact of difficulty of escape suggests egoistic motivation (Batson 1991: 116-117).

The second experiment is named "Bad News: Consequences of Carol's Car Crash" and was conducted by Toi and Batson in 1982. The participants listen to a recording in which Carol Marcy says that she broke both her legs, as a result of which she missed many classes and was threatened with having to repeat the first year of her education programme. The participants were given the chance to aid her by sparing time to help her catch up with her studies (Batson 1991: 119-120). Empathy manipulation consisted in focussing on the information of the recording (low empathy condition) or imagining how Carol feels (high empathy condition). Escape manipulation consisted in that if a participant refuses to help, she will not hear Carol again (easy escape condition) or will have to meet her as she is her classmate (difficult escape condition) (Batson 1991: 120).

The experiment result was as follows:

Easy escape and low empathy: 0.33

Easy escape and high empathy: 0.71

Difficult escape and low empathy: 0.76

Difficult escape and high empathy: 0.81. (Batson 1991: 121)

The helping result in high empathy disconfirms the AAR hypothesis predictions, because the easy escape condition does not significantly affect the helping rate. On 
the contrary, the EA hypothesis is confirmed in the high empathy condition (Batson 1991: 121). Thus, the experiment result confirms Mencius' claim that rescuing the child is not motivated by the desire to avoid an unpleasant experience.

In the above and following cases, when referring to the Mencian discussion of motivation, we should focus on the high empathy state. As regards the example provided by Mencius, it would be incorrect to refer it to the low empathy condition, especially if we consider the manipulation techniques applied in both experiments. In other words, only high empathy cases can represent ren. Considering this, the experiments conspicuously indicate that the AAR hypothesis has been disproven.

In (1), we have to consider that in helping the child the action is egoistically motivated by public opinion. In the negative version, the agent feels the pressure of morality endorsed by society and helping is motivated by avoiding "negative social evaluation" (NSE) (Batson 1991: 128). The experiment testing this motivation resorts to manipulating the level of negative evaluations in the parallel testing of the EA and NSE hypotheses on the grounds that egoistically motivated agents help only because they want to avoid the anticipated negative social evaluation, which is the ultimate goal (Batson 1991: 128). When negative social evaluation is not given, there is no egoistic goal to be reached and helping is the ultimate and altruistic goal.

This hypothesis is contrastively examined by the experiment "Loneliness of the Long Distance Student [study 2]" by Fultz et al. in 1986. The prediction for social evaluation is that helping will increase in socially evaluative circumstances. As regards the NSE hypothesis prediction, if the potential for negative evaluation is high, there will be more helping in high-empathy condition than in low. The EA hypothesis predicts that helping will be higher in high empathy contexts and lower in low empathy contexts on both levels of social evaluation (Batson 1991: 132).

The procedure involves participants-students reading two confidential letters. The first one is from Janet, a first-year student who feels lonely and is looking for a reliable friend. The second is from a professor who unexpectedly offers to befriend Janet by meeting her and staying in touch with her. On reading the first letter, the participants complete an emotional response questionnaire for the experimenter (Batson 1991: 132). The experiment involves empathy manipulation. In the low empathy condition, the participants were asked to read Janet's letter and stay objective while focussing on her communication techniques. In the high empathy condition, the participants were asked to assume Janet's perspective while reading. As for the low potential of negative social evaluation, the participant is the only person who reads Janet's notes; the questionnaires are anonymous and Janet will be contacted only if help is offered. In the case of high potential of negative social evaluation, both the experimenter and participant read Janet's notes; the examiner personally collects and compares the participants' questionnaires, and Janet will know about the participant's negative decision (Batson 1991: 132-133).

The result of the experiment is as follows:

Low potential for negative social evaluation condition and low empathy: 0.67 Low potential for negative social evaluation condition and high empathy: 1.71 High potential for negative social evaluation condition and low empathy: 1.29 High potential for negative social evaluation condition and high empathy: 2.44. (Batson 1991: 134) 
The result disconfirms the influence of NSE (helping should be high in high evaluation). The results pattern according to the EA hypothesis, where helping will increase with empathy (Batson 1991: 134). Therefore, as Mencius expected, "get[ting] in the good graces of the child's parents" (Mencius 2A6; see Lau 1984: 82) does not make the moral agent rescue the child. Help is proportional to compassion, irrespective of the possible respect earned among others.

The second type of egoistic motivation has been investigated by Smith et al., who claimed that empathically stimulated individuals are motivated by "the good feeling of sharing vicariously in the needy person's joy at improvement," and call it "empathic joy" (EJ) (Batson 1991: 153). In order to test the EJ hypothesis, in the experiment "Effect of Feedback on Helping Katie Banks" by Batson et al., the participants listened to a broadcast of Katie Banks, whose parents died leaving her with a younger brother. Helping consisted in a fund drive. Apart from manipulation consisting in perspective taking, feedback manipulation was introduced. It was considered a good way of testing the EA and hypotheses in parallel on the grounds that egoistically-motivated agents would only help once provided feedback, , by which they felt empathic joy, the ultimate and egoistic goal, as opposed to helping another, which is instrumental (Batson 1991: 154). When no feedback is provided, there is no egoistic goal to be reached and helping another is the ultimate and altruistic goal. The feedback consisted in receiving no feedback or follow-up information from Katie on her improvement. The difference in the predictions of the EJ and EA hypotheses consisted in that the EJ hypothesis predicted equally low help in a no-feedback condition regardless of the empathy levels. The EA hypothesis predicted higher help in high empathy no-feedback situations (Batson 1991: 158-159).

The result was as follows:

No feedback and low empathy: 0.33

No feedback and high empathy: 0.83

Feedback and low empathy: 0.67

Feedback and high empathy: 0.58. (Batson 1991: 160)

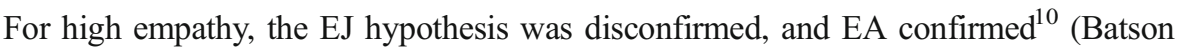
1991: 160). This confirms Mencius' dismissal of motivation directed by the desire for internal praise.

Another experiment was modified by introducing the likelihood of improvement by Batson et al: "Likelihood of Improvement and Desire for Further Exposure to a Person in Need." The story is similar to the Katie Banks story above. However, the chance for help is supplanted by being given updated information about Katie. The levels of improvement likelihood were 20/50/80\%. The predictions were that in EJ the egoistic motivation underlying choosing the second interview would grow with the likelihood. The EA prediction was that there would be more interest in a high empathy condition. As for the likelihood, most interest should be at $50 \%$ because it represents the highest uncertainty concerning the improvement (Batson 1991: 161-162).

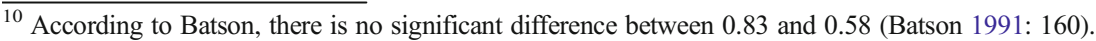


The result was as follows:

Improvement likelihood $20 \%$ and low empathy: 0.22 Improvement likelihood $20 \%$ and high empathy: 0.50 Improvement likelihood 50\% and low empathy: 0.33 Improvement likelihood 50\% and high empathy: 0.67 Improvement likelihood $80 \%$ and low empathy: 0.44 Improvement likelihood 80\% and high empathy: 0.44. (Batson 1991: 162)

The experiment confirms the EA hypothesis for high empathy (Batson 1991: 162-163). The Mencian claim that the moral agent does not calculate the possibility of emotional self-satisfaction is confirmed. Thanks to compassion, she is concerned with the child's well-being, which manifests her altruistic ren.

From the perspective of the Mencian conception of motivation, the value of the experiments lies in showing that Mencius was right in that the three egoistic motivations are not underpinned by compassion. The argument strength provided by the experiments from Batson's study can be primarily attributed to how they were engineered. The situational design as well as the specific parametric manipulation of the staged situations maximally reduced any possible interferences with other possible motivations than the one being examined. This precise and systematic approach, although not absolutely perfect, carries more weight than intuitions formed from a subjective perspective.

Apart from benefitting the Mencian conception alone, experimental psychology argumentation also enables opposite theories to be confronted through empirical criteria. It seems that experimental methodology can contribute to developing a new language for comparing at least some conceptions from different philosophical traditions.

\section{Methodological Conclusions}

The above employment of psychological experiments as argumentation in Confucian ethics invites some methodological conclusions. Contemporary philosophical research in the West, thanks to its perennial interspersion with science, has smoothly integrated with other disciplines, which is not only to be found in cognitive science, but also in the discussion of originally philosophical issues belonging to, for example, epistemology (e.g., David Chalmers), aesthetics (e.g., Gabrielle Starr) or ethics (e.g., Jesse Prinz). The meeting of Chinese philosophy with scientific evidence is only recent and still beyond mainstream research. However, its integration with cognitive science or psychology, ${ }^{11}$ for instance, testifies that it should not be excluded from naturalized philosophy research.

Undoubtedly, experimental psychology evidence contributes to moral philosophy. When philosophers address issues connected with human behavior, thoroughly conducted experiments undoubtedly guarantee a higher accuracy of data to work on than an individual philosopher's perspective, from which human

\footnotetext{
$\overline{11}$ A good recent example of such integration is the first chapter, devoted to moral psychology, of Bruya 2015.
} 
reactions are predicted. Representative groups, adequate manipulation, and other factors, including cultural ones, do not guarantee perfect accuracy, but they are far more reliable than many unsystematic examinations underlying philosophical statements. Batson's study of altruism is a good example of how intuitions connected with morality can be empirically investigated with a high degree of precision.

As I mentioned at the beginning of my article, psychology evolved from philosophical investigations and the questions it addresses still often overlap with what interests contemporary philosophers. This is also the case with experimental psychology, whose combination with philosophical enquiries has given rise to experimental philosophy. As Joshua Knobe et al. concluded in their article "Experimental Philosophy," the collaboration between the two disciplines can be viewed as "a return to a more traditional conception of how psychology and philosophy should relate and develop" (Knobe et al. 2012: 96). Comparative philosophers are not excluded from this methodological merger. Their discipline is situated even closer to experimental psychology evidence than that of philosophers working in one tradition, which is often raised to the universal level. The particular sensitivity of comparative philosophy to a cultural or even civilization context requires more concern with experimental evidence, which emphasizes the importance of cultural psychology in particular. Cultural psychology is particularly aware that the reliability of experiment results depends on considering the participants' cultural background, which has been proven in numerous experiments by, for instance, Richard Nisbett and Masuda Takahiko. ${ }^{12}$ This is reflected in experiment methodology, which is sensitive to the cultural (or even subcultural) variability among the subjects. ${ }^{13}$

Whereas evidence provided by cultural psychology benefits comparative philosophy in an almost evident way, one may pose the question if cultural psychology can benefit from comparative philosophy contribution. The example of experimental philosophy research seems to answer this question positively. Cultural psychology benefits here mostly in theoretical-methodological respect. Experimental methods do not always suffice to critically reflect upon or transcend certain established narrations of reality. This faculty belongs to philosophical reflection, which is able to build alternative theoretical models, some of which can be tested by experimental sciences.

Justin Garson's discussion of Batson's study concerning egoistic motivation showcases how philosophy can question experimentally-confirmed hypotheses. He points out that the experiments discussed by Batson disprove one hypothesis at a time and regardless of how many other hypotheses can be tested, they only eliminate single egoistic motivations (Garson 2015: 15-16). In his opinion, one can entertain a different conception of egoistic motivation, namely that people are simultaneously motivated by multiple desires. One of them can be disjunctive desire, according to which human motivation instead of being reduced to one single desire is

\footnotetext{
12 The cultural sensitivity in cognition, and what follows, behavioral repertoire has also been confirmed in neuroscientific experiments by, for example, Georg Northoff and HaN Shihui (Han and Northoff 2008).

${ }^{13}$ This can be exemplified with experiments conducted by WANG Qi, a psychologist preoccupied with autobiographical memory development. Her experiments test hypotheses across culturally different groups, mostly Chinese/Taiwanese and European-background American subjects to show possible cross-cultural differences in memory development (Wang 2006, 2008).
} 
driven by an alternative of them (Garson 2015: 16). Since the experiments do not consider this conception of human motivation, philosophical insight in this respect can significantly contribute to the improvement of them. In other words, philosophical models can influence experiment models.

Extending the analogy to cultural psychology and philosophy is by all means legitimate. Whereas the comparative value of experiments is undeniable on account of underscoring possible cultural differences in behavior, the theoretical construction raised on them may prove to be fallible. A lack of philosophical engagement providing alternative conceptions may lead to conclusions drawn too hastily regarding what guides human behavior in specific cultures. ${ }^{14}$

The lack of traditional ties between Chinese philosophy and science has not prejudged the contemporary methodical development of the latter. Chinese philosophy starts to turn toward scientific evidence. This fact does not only testify that Chinese philosophy can be included in naturalized philosophy research. It seems that it can also pose a more general methodological question.

The fact that comparative philosophy deals with thought systems of different cultural provenance necessitates a different methodological approach than in the case of focusing on a single philosophical tradition. Comparative methodology is deeply concerned with revealing possible conceptual and heuristic (in)commensurabilities in order to produce a unifying discourse supervening on them. In other words, we have a unifying methodology built on culturally discrete materials. Considering this, it seems that integrating Chinese philosophy with naturalized philosophy research cannot be accommodated by the comparative approach for two reasons. First, the methodological objective is not comparative. It does not involve showing how given philosophical systems vary with regard to a particular question but is more concerned with integrating them in approaching a philosophical issue. Regarding moral nature, for instance, comparative philosophy would be more concerned with how it is viewed from different philosophical standpoints, whereas in the "integrated" approach more consideration would be given to how moral nature can be understood from a perspective combining the two (or more) traditions.

Second, although comparative philosophy creates space where different philosophical traditions can be encapsulated in one philosophical language, it treats the material it works on as culturally discrete. Combining Chinese philosophy into naturalized philosophy discourse is more inclined toward seeing the different traditions as one, varied, yet indiscrete. This can be compared to cultural globalization processes, where local cultures are no longer perceived separately but rather merging with the global cultural landscape.

Considering the above reasons, one can expect that the ongoing integration of Chinese philosophy with experimental psychology as well as other empirical sciences is likely to make a methodological contribution to philosophical research not only in the comparative respect.

\footnotetext{
${ }^{14}$ A good example of such philosophical contribution is Seok's critical paper on Nisbett's claim that Asians' integration of opposite judgments can be attributed to change as the primary principle (Seok 2007: 233). By referring to selected Chinese philosophy source texts, Seok shows that holism is a more fundamental conception that underlies the way in which Asians think about the world, and that it provides a more legitimate interpretation of Nisbett's experiments under discussion.
} 
Open Access This article is distributed under the terms of the Creative Commons Attribution 4.0 International License (http://creativecommons.org/licenses/by/4.0/), which permits unrestricted use, distribution, and reproduction in any medium, provided you give appropriate credit to the original author(s) and the source, provide a link to the Creative Commons license, and indicate if changes were made.

\section{References}

Ames, Roger T., and Henry Rosemont, trans. 1998. The Analects of Confucius: A Philosophical Translation. New York: Ballantine Books.

Analects (see Ames and Rosemont; Waley).

Batson, C. Daniel. 1991. The Altruism Question: Toward a Social-Psychological Answer. New Jersey: Lawrence Erlbaum Associates. 2011. Altruism in Humans. Oxford: Oxford University Press.

Bruya, Brian. 2015. The Philosophical Challenge from China. Cambridge, MA: The MIT Press.

Darwall, Stephen. 1998. “Empathy, Sympathy, Care.” Philosophical Studies 89: 261-282.

Garson, Justin. 2015. The Biological Mind: A Philosophical Introduction. New York: Routledge.

Han, Shihui, and Georg Northoff. 2008. "Culture-sensitive Neural Substrates of Human Cognition: A Transcultural Neuroimaging Approach.” Nature Reviews Neuroscience 9: 646-654.

Hursthouse, Rosalind. 2013. "Virtue Ethics." In Stanford Encyclopedia of Philosophy (Fall 2013 Edition), edited by Edward N. Zalta. http://plato.stanford.edu/archives/fall2013/entries/ethics-virtue (last access September 14, 2015).

Knobe, Joshua, Wesley Buckwalter, Shaun Nichols, Philip Robins, Hagop Sarkissian, and Tamler Sommers. 2012. "Experimental Philosophy." Annual Review of Psychology 63: 81-99.

Lau, D. C., trans. 1984. Mencius. Middlesex: Penguin Books.

Legge, James. 1985. The Works of Mencius. New York: Clarendon Press. In Chinese Text Project, edited by Donald Sturgeon. http://ctext.org/mengzi (last access July 28, 2016).

Lokhorst, Gert-Jan. 2016. "Descartes and the Pineal Gland." In Stanford Encyclopedia of Philosophy, edited by Edward N. Zalta. http://http://plato.stanford.edu/entries/pineal-gland/\#3 (last access May 13, 2016).

Mandeville, Bernard. 2010. The Tale of the Bees or Private Vices. Indianapolis: Liberty Fund.

Markosian, Ned. 2008. "Restricted Composition." In Contemporary Debates in Metaphysics, edited by Theodore Sider, John Hawthorne, and Dean W. Zimmerman. Malden-Oxford-Victoria: Blackwell Publishing.

Mencius (see Lau; Legge; Van Norden).

Mencius (Mengzi 孟子). 2007. Translated and annotated by WAN Lihua 萬麗華 and LAN Xu 藍旭. Beijing 北京: Zhonghua Shuju 中華書局.

Nisbett, Richard. 2003. The Geography of Thought: How Asians and Westerners Think Differently... and Why. New York: The Free Press.

Priest, Graham. 2003. "Where Is Philosophy at the Start of the Twenty-First Century?" Proceedings of the Aristotelian Society 103.1: 85-99.

Sartre, Jean-Paul. 2007. Existentialism is a Humanism. Trans. by Carol Macomber, edited by John Kulka. New Haven and London: Yale University Press.

Slingerland, Edward. 2008. What Science Offers the Humanities. New York: Cambridge University Press.

Slingerland, Edward, and Mark Collard, eds. 2012. Creating Consilience: Integrating the Sciences and the Humanities. New York: Oxford University Press.

Seok, Bongrae. 2007. "Change, Contradiction, and Overconfidence: Chinese Philosophy and Cognitive Peculiarities of Asians." Dao 6.3: 221-237.

Van Norden, Bryan W., trans. 2008. Mengzi: With Selections from Traditional Commentaries. Indianapolis and Cambridge: Hackett Publishing Company.

Varela, Francisco J. 1999. Ethical Know-How: Action, Wisdom, and Cognition. Stanford: Stanford University Press.

Waley, Arthur, trans. 1997. The Analects: Chinese-English Bilingual Edition 論語: 漢英對照. Beijing 北京: Waiyu Jiaoxie Yu Yanjiu Chubanshe 外語教育與研究出版社.

Wang, Qi. 2006. "Earliest Recollection of Self and Others in European American and Taiwanese Young Adults." Psychological Science 8.17: 708-714.

2008. "Emotion Knowledge and Autobiographical Memory across the Preschool Years: A CrossCultural Longitudinal Investigation.” Cognition 108: 117-135. 